\title{
EXPLORING GOVERNMENTAL COMMITMENT TO EXECUTE INCLUSIVE EDUCATION IN ETHIOPIA
}

\begin{abstract}
Mainly, the aim of the research was to explore the absence of governmental commitment and find out the structural barriers that hindered the execution of inclusive education in Ethiopia. Exclusionary issues that Ethiopian schools face today are highly related to ignorance and lack of commitment that stem from education authorities and even from teachers of students with disabilities. Subsequently, I employed qualitative approach under the hegemony of constructivism paradigm to locate where the barriers of inclusive education stemmed from. The hermeneutic design of the study enabled me to build knowledge about the barriers that hindered the execution of inclusive education from governmental commitment perspective. Using semi-structured interview and focus group discussion as instrument, I listened to personnel in the education system. Thereafter, the data analysis went by transcribing the recorded interview verbatim. Then, using the transcribed and chunked data, I mapped the range and nature of phenomena, created typologies and found out associations between themes with a view to provide explanations for the findings. The process of mapping and interpretation was also guided by the original research aims as well as by the themes that have emerged from the data themselves. The participants' account witnessed and construing the data, therefore, the challenges to implement inclusive education ranged from the absence of mandatory national inclusive policy to the inconsistent data about children with disabilities. Finally, I have recommended collaborative effort among stakeholders to ensure inclusion of children with disabilities.
\end{abstract}

Key words: absence of inclusive policy, children with disabilities, execution, inaccessibility, inclusion, inconsistent data, governmental commitment, structural problem.

\section{Introduction}

Traditionally, children with disabilities and those with other special educational needs have experienced exclusion, discrimination and segregation from mainstream education and their peers (Tirussew, 2006; UNESCO, 2003). As Tirussew (2005) reported, some of the children with disabilities in Ethiopia are placed in separate classes or schools; many have been denied access to education of any sort. However, the fundamental principle of inclusive schooling fixes itself on the notion that all children are best educated together in age-appropriate, heterogeneous classrooms, wherever possible, with necessary supports and services (UNESCO, 1994; 2003). As different documents by UNESCO show, inclusive education initiatives often have a particular focus on those groups, which, in the past, have been

\footnotetext{
'zelalem950@gmail.com
} 
excluded from educational opportunities (UNESCO, 2005). Despite encouraging developments, there are still cases where a great number of children who are not attending school. Ninety percent (90\%) of them live in low and lower middle-income countries and over 80 million of these children live in Africa (WHO, 2011). As Zelalem (2018) noted, alarmingly, the countless other children with disabilities within the school system are being excluded from quality education. Moreover, among those who do enrol in primary school, large numbers drop out before completing their primary education.

As Ethiopia is one of developing sub-Saharan countries, creating accessible education for children with disabilities has been highly challenging issue for both the government and the family of children with disabilities (Tirussew, 2006; Lewis, 2009). Even, the exact number of children with a disability in Ethiopia is not known. However, WHO (2011) estimated that $15 \%$ of people in any population have a disability. Accordingly, from the school- age population of 33.5 million, the school population of children with disabilities had to be 5 million (Ministry of education, 2015). Nevertheless, as the same document in 2013/14 only 77,850 children (42\% girls and $58 \%$ boys) visible children with disabilities are documented as enrolled in Grades 1 to 12 (Ministry of education, 2015). Currently, information on children with special educational needs who are enrolled in pre-primary is not collected yet. With regard to primary education only $4 \%$ of the estimated children with special needs are enrolled, which is a barrier to the achievement of universal primary education.

There is no special transport arrangement for students with disabilities. Hence, inaccessibility of education is one of its major facets. Poverty and disability have also worsened the situation. Despite the large number of people with disabilities, the provision of special needs education and other services is extremely limited (Lewis, 2009). The development of special needs education is very slow and many children with disabilities are still kept away from schools and other services. The erroneous understanding of disability and its association with moral wrongdoing forces parents to hide their children with disability at home, to be ashamed of them and to undermine the child's potential to learn and lead an independent life (Tirussew, 2005).

There has never been a placement service in the school system which makes assessment at entry point to help these children who need back-up support. Consequently, most of these children seem to be left without any educational support (Moe, 2016; World Vision, 2007). As a result, they often suffer from psychological and academic difficulties and are intended to leave school early in life without success. In line with this, there is no responsible body in the education sector to ensure accessibility of the classrooms, school facilities and the school compound at large (Tirussew, 2006; World Vision, 2007). Tirussew (2006) argues that although children with disabilities have been attending mainstream schools, their problems and needs are often not recognised, which has contributed to the alarming early school dropout rate in the country. As Tirussew (2006) highlights, Ethiopia has very few early childhood development programmes. Those that do exist are primarily urban-based. This means that many children are not receiving the early support they need (MoE, 2012). In particular, the needs of children with disabilities are not being identified before they start school, which means many children with special needs subsequently drop out in the first grade, when they find that their school cannot offer quality education that responds to their needs (World Vision, 2007). 
With all these, World Vision (2007) reports that children with special needs in Ethiopia could not go to school because teachers are not patient with them in the mainstream schools and non-disabled students do not understand their difficulties. On the contrary, there are very few schools in special needs education system, which are too far from home and too expensive. The country's SNE programme strategy indicates that teachers' lack of awareness of all children's rights to education and lack of political commitment are key reasons for children with special needs being turned away from mainstream schools (MoE, 2012). The strategy again highlights that special units, special day schools and residential schools are mostly confined to urban areas and have long waiting lists to register students with disabilities (MoE, 2012; Tirussew, 2005). Furthermore, the strategy noted that the ESDP II allocated a persistent budget to special needs education, yet regions did not report on any activities or expenditure under this budget component. Special schools and units apparently had their budget requests disapproved and the strategy attributes this to the lack of awareness and knowledge about special needs education among district officials (MoE, 2012; Tirussew, 2006).

As ministry of education (2015) documented in its educational sector development plan, the eminent factors that hindered the integration of children with disabilities are: lack of awareness; lack of knowledge, skills and commitment to implement activities to support SNE, which is true from the federal to the school level; lack of reliable data to help understand the status of children with special needs and target suitable interventions; absence of clear structure for coordination and administration of SNE issues from federal to district and school levels; absence of a financing mechanism to support SNE and inclusive education; poor school infrastructure, facilities and adapted teaching and learning materials for SNE along with the lack of standards and guidelines; and weak pedagogical skill of teachers for special needs education. In Ethiopia, from many other things, several prominent factors hindered school enrolment of children with disabilities. These include lack of sign language skills among teachers, resource and infrastructure constraints and inflexibility of curriculum, and teachers' lack of information and training on how to adapt teaching methods for children with special needs (Tirussew, 2006). Hence, in Ethiopia, teachers find it difficult to accommodate students with SEN, and compel them to adapt to the school environment instead of adapting the school to the needs of the students (World Vision, 2007). Even those who have access to education are not equipped with modified teaching material and assisted trained teachers as well as have no modified environment. This either shows that the implementation of inclusive education is a dream or at its peak of challenge in the context of the country.

\section{Theoretical framework}

The theory of ecology of human development of Bronfenbrener (1989) offered me a lens to examine barriers that Ethiopian children with disabilities faced to be educated in an inclusive setting. With the lens of system theory, the study has identified barriers that hindered the execution of inclusive education ranged from micro-level to Macro-level within the ecologicalsystem. Subsequently, the findings of the current study reveals that most of the challenges that the country faced to implement inclusive education steamed from the bi-directional and interactions of the child with disability and the environment within the ecosystem.

\section{Methods}

Under the qualitative approach, the researcher employed phenomenological design to identify barriers of inclusive education based on the experiences of the research participants. 
According to Van Manen (1990), the focus of phenomenological inquiry is what people experience with regard to some phenomena or other and how they interpret those experiences. Therefore, focus of phenomenological inquiry is what people experience pertaining to some phenomena or other and how they interpret those experiences that they have in relation to execute of inclusive education (Creswell, 2007; Van Manen, 1990).

\section{Location}

As the title of the research tells, the study was conducted in Ethiopia at national level. The country has nine regional states and two administrative cities. The research located itself in three regional states and one administrative city out of nine regional states and two administrative cities, namely, South Nations, Nationalities and Peoples, Amhara, Tigrai regional states and Addis Ababa administrative city. These sample areas were selected purposefully since they have a better number of children with disabilities and made effort to attempt the practice of inclusive education.

\section{Sampling}

For the purpose of this study, I employed judgemental sampling. According to The American Heritage College Dictionary (1993, p. 1206), a sample is "a portion, piece, or segment that is representative of a whole." In addition, sampling is "an act, process, or technique of selecting an appropriate sample". Therefore, sampling is a concept that transcends research studies in general and research paradigms in particular. The researcher attempted to obtain a sample that appears to be resourceful of the population (Bhattacherjee, 1998). Judgemental sampling is the most common sampling technique in qualitative research (Martin \& Marshall, 1996). Therefore, the researcher selected the most productive samples to answer the research question. Semi-structured interview and focus group discussion have been employed to collect data from experts, supervisors, officers in the ministry of education and regional bureaus.

\section{Procedure}

The process of data collection went after the approval of the instrument by the supervisor and getting the ethical clearance from ethical committee of the University of South Africa. Subsequently, letters of requesting permission had been dispatched from the ministry of education of Ethiopia to each Regional Education Bureaus. This enabled me to access the necessary documents like workshop proceedings, office minutes, guidelines, and other relevant documents in relation to inclusive education. However, I offered personal request for individual participants of the research. The next step was to translate the English version of the instrument into Amharic in order to avoid language barrier among interviewees and focus group discussants.

\section{Data analysis}

In this section of the research, the focus of analysis was on content, context, and interpretative comments. In selecting themes, it was important not only to take into account prevalence of data but also the richness of the extracts and their capacity to highlight the themes and enrich the account as a whole. 
According to Creswell (2007) and Van Manen (1990) note, in phenomenological interpretive analysis, there are four stages of analysis. During the first stage, it was important to read the whole transcript more than once and record some observations and reflections about the interview experience in a separate reflexive notebook and textual analysis. During the second stage, it was demanding to return to the transcript to transform the initial notes into emerging themes. Here, my task was to formulate concise phrases that contain enough particularity to remain grounded in the text and enough abstraction to offer conceptual understanding. In third stage of analysis, my task was to examine the emerging themes and clustering them together according to conceptual similarities. The task at this stage was to look for patterns in the emerging and pre-set themes and produce a structure that will be helpful in highlighting converging ideas. The themes subsequently, enabled me to prepare starting points for writing up a narrative account of the research. The trustworthiness of this research was also ensured using reflexivity, audit trail, triangulation, peer debriefing, member checking and prolonged engagement in the process of data collection and intensive reading.

\section{Result}

This section of the research presents the findings in relation with the research questions and other emerged themes. As the purpose of the study was to explore barriers in relation with government commitment that Ethiopia faced to execute inclusive education, the lived experience of six personnel in the education system took part in the research. Subsequently, I went on the analysis with those themes which represent the basic and sub-questions of the research and others which emerged throughout data gathering.

\section{Themes developed from focus group discussion Absence of inclusive policy}

The participants perceived as anything which containing a word 'inclusive' is regarded as a policy. For instance,

Discussant A: "Ethiopia has inclusive education policy."

Discussant B: "There is strategy to execute inclusive education."

Discussant C:

"The term inclusive education is prevalent in many documents."

Discussant D: "The strategy document calls for all "children with and without special needs to learn together."

To the contrary of four discussants, two of participants remarked as there was no policy in the area as follows.

Discussant E: "There is no independent policy like; gender, HIV, children and other social issue policies."

Discussant F: "There is the term 'inclusive' is common but no practice."

None of the discussants mentioned clearly which policy deals with inclusive education. Even the respondents didn't cite the article which deals with inclusive education clearly in the education policy. The good thing was that the participants finally admitted as there was no even guideline to execute inclusive education at both regional and national level. What I have observed from the discussion was that the discussants were highly defensive about the government documents. 


\section{Lack of political commitment}

As all of the participants agreed, if politician had commitment, they could play a vital role to implement inclusive education.

Discussant A: "Nothing is done without the knowledge of the political leaders."

Discussant B: "Oh! It is obvious. The political system decides everything." The discussants' account revealed to what extent the political leaders could play a vital role to execute any programme including inclusive education. However, lack of commitment is observed among political leaders. Three of the discussants have evidenced this with the following account.

Discussant C: "No guideline."

Discussant E: "No clear direction about the execution of inclusive education."

Discussant F: "The government paid less attention for the execution of inclusive education. As a result, school population with disability accounts only $4 \%$.

\section{Ignorance of stakeholders about children's right to education}

As it is believed, stakeholders of education are parents, children in schools, teachers, school principles and supervisors, experts, and officers in the education system. However, there is such discrepancy among stakeholders of education regarding the right of children with disabilities to education.

Discussant A: "Parents of children with disabilities sometimes aren't willing to send their children to schools. Even when they are invited to send, they keep quite."

Discussant B: "During supervision, we priortise the majority/children with no disabilities."

Discussant C: "Yes, children with disabilities have the right to education."

The recognition of the right of children with disabilities to education varies from stakeholder to stakeholder. Though there was no consistency among discussants, some told me as stakeholders of education have recognised the right of children with disabilities to education. Whereas, others stakeholders couldn't recognise the right of children to education fully.

Discussant E asked: "Do you know? The awareness level varies from person to person." Meanwhile of our discussion, the participants of the study contradicted one another. For instance, at the beginning of our discussion, they had told me, as it was possible to say that stakeholders of education have recognised the right of the children to education. However, later in the discussion, the discussants admitted as there was a gap obviously regarding recognition of the right of children with special needs. If it hadn't been, the children would have been included in the regular schools rather than be segregated in special units. As they witnessed, the inaccessibility of education bureau itself, insufficient budget allocation and unavailability sign language interpreters in schools could be evidence to what extent the education system was ignorant of the right of children with special needs to education.

\section{Inaccessibility of school environment}

As discussants unanimously agreed, in addition to the unfriendly topography, most buildings including schools are not designed in a welcoming manner to people with disabilities. The discussants have confirmed the fact this way; Discussant A: "Most schools are inaccessible and remote." 
Discussant B: "Look! It is education bureau. It is with three floors. But it doesn't have either ramp or lift."

The observable fact was that fulfilling infrastructure seems challenging for the executer since schools dispersed and was remote to most villagers in the country to execute inclusive education. Pathways from home to schools are cliffy. With all these; children with motor and visual disabilities particularly have encountered difficulty primarily to go school to the worst to integrate themselves with non-disabled children in school activities. The participants have also substantiated the information with the statements which come hereafter.

Discussant D: "The entrance of school gates isn't well built to allow wheelchair users."

Discussant E: "Mostly, classroom to classroom movement is difficult."

As the discussants have reported, students with visual and physical disabilities faced physical barriers to move about inside primary schools. Most pathways are cliffy, ridge and sloppy. To jump such ways was difficult task for students with physical and visual disabilities as most of the participants of focus group discussion were of the same mind.

\section{Themes developed from semi-structured interview with professionals of special needs education}

\section{Inconsistent data}

Like other things, inconsistent data of number of people with disabilities has been identified as one of barriers of inclusion of the group. Participants have substantiated the fact in this way. Participant A remarked: "We usually obtain different figure; in one village, for instance, we collect sometimes 100, 90, and the other time; 101 and so on."

Participant B: "There is data inconstancy regarding PwDs."

Data is very important to distribute resources accordingly. However, the interview vetted the presence of data inconsistency regarding children with disabilities. Regarding this, the participants said the following.

Participant A: "We don't know the number of special classes, inclusive schools and special day schools."

Participant B: "We don't have the exact number of learners with special needs to distribute teaching aids."

In this regard, there was no consistent data about disability across the nation. With no accurate number of $\mathrm{CWDs}$, it seems difficult to facilitate schools with adapted teaching material and follow up the education of the group.

\section{Structural problem}

Inclusive education is addressing the diverse need of learners. To execute inclusive education, therefore, the education system is to be structurally responsive to the diverse need of citizens. However, the existed practice was the opposite. In line with this, the interviewees have reported their experience to maintain the above statement.

Participant A: "If we were able to hire experts of special needs education at all level of the education system, it would be possible to follow -up the inclusion of CWDs." 
Participant B: "No expert in special needs education at zone and district level."

Administratively, the country follows a federal state structure. Following this, there are different administrative structures from the top the federal state to the bottom "Kebelie" level. Structurally, the education system was not responsive to specific needs of CwDs. As the data reveals, the civil service structure didn't allow the education bureaus to hire experts at zone, "Wereda/district" and "'Kebelie"” level. This in turn, has left CwDs aside of education without concerned body. Since there was no an expert in special needs and inclusive education, the inclusion of children with special needs has been barriers.

Again, as one of the interviewee told me, there were discriminatory documents against people with disabilities in the structure of the education system. For instance,

Participant A: "According to the teacher selection criteria document; a teacher should be more than 1.45 metres, not blind to lower grades, not deaf teacher for students in first and second cycle."

Based on the above account, the structure with different manifestation has hindered the execution of inclusive education at all level. Referring teacher selection criteria which discriminated teachers with disabilities in the MoE, it was undoubtedly clear how much the presence of discriminatory documents in the structure hindered the realisation of inclusion.

\section{Discussion}

The result of interview and focus group discussion data have been amalgamated in to six identified themes to ensue the discussion. Accordingly, the themes/ barriers, which stemmed from lack of governmental commitment, have been synthesised in relation with ecology of human development. For instance, at meso level; inaccessibility of school environment and ignorance of stakeholders of the right of children with disabilities to education, at exo level; inconsistent data and structural problem, and at macro level; lack of political commitment and the absence of inclusive policy were the barriers that the researcher located in accordance to theoretical framework to guide the study. The discussion has therefore, folded a range of matters that conspicuously hindered the effective execution of inclusive education in Ethiopia and went on thematically likewise the previous section of the research.

\section{Inaccessibility of school environment}

Ethiopia is one of underdeveloped sub-Saharan countries where the infrastructure is not yet well constructed. In addition, houses were dispersed, schools were far-flung, and the topography is rugged. As a result, pathways from home to schools were cliffy. In addition to the unfriendly topography, most buildings including schools were not designed in a welcoming manner to people with disabilities (Zelalem, 2018). Similarly, the study found out that all these geomorphological obstacles have been identified as major barriers to ensure full inclusion of CwDs particularly for those who have mobility problem.

Here, one of the participants noted his observation as follows: "Look! It is education bureau. It is with three floors. But if a person with physical disability or wheelchair user comes, no way to talk to the head. Unless and otherwise, somebody can carry him/her." The above quotation proved how geomorphological accessibility became a barrier on the top to prevent inclusion. Naicker's (2006) study corroborates the findings of this study when reporting that this way, a 
person with physical disability using a wheelchair for instance, required a ramp to gain access to a mainstream school, which was not provided for by the system. As the same author noted, access to education was prevented as a result of barriers that reflect the incapability of the system rather than the incapability of the person (Naicker, 2006).

Children with disabilities were facing physical barriers not only outside schools. They were confronting the physical barriers even within schools. The data confirmed that children with motor and visual disabilities particularly have encountered difficulty primarily pertaining to going to school to the worst to integrate themselves with non-disabled children in school activities. This finding is consistent with the findings of Mukhopadhyay (2014). As he discovered in Botswana, structural barriers limited the independent access to classroom and school activities, and impacted the participation and competence negatively the curricular and co-curricular activities of students with mobility limitation.

Personnel in the education system pointed out that buildings in most mainstream schools were not constructed with people with disabilities in mind. As it was clearly indicated in the data, the poor infrastructure together with, pathways to classroom, offices, guidance, and counsellors challenged students with disabilities not to come to school and not to have active participation in the learning process as well. Entirely, the primary schools had full of up and down topography, the inclusion of children with mobility impairment had been at its challenge. As a result, the observable fact was that fulfilling infrastructure seems challenging for the executors.

\section{Ignorance of stakeholders about children's right to education}

The current study reveals that stakeholders in education can include teachers, parents, school principals, and students with and without disabilities. The data reveal the extent to which these stakeholders were unaware about the right of children with special needs to be included in the regular schools. Among the stakeholders, teachers are believed to have a better awareness than others. However, even teachers in Ethiopia were not aware of the benefits of inclusive education. This finding has been backed by the findings of Zelalem (2018). In his study that he has analysed "School challenges of students with visual impairment," he found out that teachers believed that inclusion of children with special needs would not bring academic and social benefit for the group.

Hence, a gap obviously is observed regarding recognition of the right of CwDs to education. If stakeholders in education had not been ignorant of the right of children to inclusion, the children would have been included in the regular schools rather than be segregated in special units. Evidently, the data indicates that the inaccessibility of education bureau itself, insufficient budget allocation and unavailability of sign language interpreters in schools indicates the extent to which the education system, which is the one among other, stakeholders was ignorant of the right of children with disabilities to education. I have observed that each stakeholder from top to down even to parents did not recognise sufficiently the right of CWDs to education. Similarly, Lazarevic and Vukasinovic in their study of Serbia (2013) have identified as stakeholders (teachers and parents of CwDs) were in completely different positions regarding the education of children with disabilities. Wook (2013) has also echoed stakeholders' ignorance as impeding factor to ensure inclusion of children with disabilities in his finding. 


\section{Inconsistent data}

Because of cultural prejudice and societal discrimination, families do not want to expose their CwDs. As a result, it has been challenging to have accurate data about PwDs for health and other services (WHO, 2011; Wapling 2016). Similarly, the current study identified that there was no accurate data in the study regions regarding students with special needs. In line with this, researchers proved the presence of little data on CWDs and what evidence does exist is based on a smaller set of studies than available for most other non-disabled children (Cortiella \& Horowitz, 2014; Wapling, 2016).

Even the data that exist in different offices of the hierarchy of the education has been inconsistent and would not give a real picture about the actual number of PwDs in general and CWDs in particular. Therefore, it has been found out that not only accurate data but also data inconsistency is one of the most challenging issues to execute inclusive education in Ethiopia. Hence, as the data witnessed, the very observable fact is that all of the participants of the research from top (education heads) to the bottom (school supervisors) were not aware about the actual number of students with disabilities whom they were serving in their respective regions. The federal government as well as Regional Education Bureaus did not establish database either for research purpose or service delivery for children with disabilities yet. Therefore, there was no office or sector in the education system that had consistent data about disability across the nation. In support of this, Wapling (2016) found out as absence of information is a prevalent phenomenon relating to data on numbers of CWDs in most African countries.

The country may have economic constraint to furnish all schools with adapted materials and special equipment in order to create access for CwDs. For this, identifying schools those that enrolled students with special needs and having consistent data of the number of CwDs would be indispensable fact as precursor to actualise inclusivity.

With no accurate number of CwDs, it seemed unrealistic to facilitate all schools with adapted teaching material and follow-up the education of the children. The absence of accurate and inconsistent data reciprocally has hindered the execution of inclusive education in Ethiopia (MoE, 2016; Zelalem, 2018).

\section{Structural problem}

Inclusive education is everywhere and for everyone. To realise this fact, responsive personnel is required in the administrative structure of the education system. When the reverse is the case, the execution of inclusive education would be at risk (Malak, 2013; Maguvhe, 2015). This was a slowdown incidence to ensure the inclusion of CWDs where the current study has been conducted. Administratively, the country follows a federal state structure. Following this, there are different administrative structures from the top the federal state to the bottom "Kebelie" level.

However, except at federal, Regional Education Bureau and zonal level. Even at zone level, the assigned personnel were not most often professional. To the worst, the rest hierarchies (Wereda/district and "Kebele") levels do not have the personnel to follow-up the education of CwDs. The last two administrative structures are the grassroots where the children are at hand. Since there were no experts in special needs education at Wereda/district and "Kebele," 
no effort has been made to increase school enrolment of CWDs. In line with this, as two researchers from Nigeria noted, when people in the administration of SNE at various levels of administrative structure are non-professionals, a task to facilitate inclusion of children with special needs might be left without the owner (Adebisi et al, 2014).

Though some are coming to schools, they used to travel a distance to reach special units where adapted school materials were available. As a result, the principle of inclusion has been compromised. To execute inclusive education, therefore, the education system is to be structurally responsive to the diverse need of citizens. Otherwise, with the absence of clear line of responsibility and mechanism for coordination, monitoring and reporting across sectors, issues of inclusion would be pushed to the corner (Zelalem, 2018). However, the existed practice was the reverse. For this and as the data reveal, the civil service structure did not allow the education bureaus to hire experts at zone, "Wereda/district" and "Kebelie/county" level. This in turn, has left CwDs aside of education without concerned body. Because the education bureaus at region level could not hire experts at grassroots level, the education system has faced gigantic challenge to actualise the principle of inclusive education.

As respondents confirmed, a document that discriminates against the equal opportunity of teachers with disabilities to execute. According to the teacher selection criteria document, a teacher should be more than 1.45 metres, not blind to lower grades, not deaf teacher for students in first and second cycle.

Based on the above discriminatory document in the MoE, the study has identified the structure barred the execution of inclusive education at all levels. Referring to teacher selection criteria that discriminated teachers with disabilities in the MoE, it was undoubtedly clear how much the presence of discriminatory documents in the structure hindered the realisation of inclusion.

\section{Absence of inclusive policy}

As the finding portrays, the discussants had two different views about the presence of inclusive policy. However, the available documents and the final account of the discussants proved that the country does not have inclusive education policy. For instance, Article 3.2.9 of the education and training policy (2012) stipulated this statement: "Special education and training will be provided for people with special needs (p.17)". It is possible to conclude from the above statement as the education and training policy of Ethiopia is not inclusive. Rather, the phrase 'special education' in the quotation reveals the medical model approach that the policy has intended to follow. Whereas, education sector development programme (ESDP) of 2015 remarked about the population of students with special needs in the primary schools. Nonetheless, the document has nothing about the education strategy that Ethiopia follows to educate children with special needs.

The absence of inclusive policy has obviously hampered the effect of inclusive education in Ethiopia. As a result, with no such mandatory policy, facilitating inclusive education seems unrealistic. With similar finding, Thomas (2013) has remarked, inclusive policy would make inclusion mandatory, and could force authorities to deploy resources and other support services to ensure implementation. Policy might result in clear directions and execution strategies (2013). 
As UNESCO (2009) noted, policy is something that governs the direction and overall execution of what it is intended for. Hence, policy is more than guideline, strategic plan and any other document. However, the participants of the current study perceived policy as a piece of document. Therefore, for them, even strategic plans are policies though the country does not have one yet. Hence, it is possible to conclude that the country does not have influential document to execute inclusive education other than strategic plan of 2012 (MoE, 2016). Undoubtedly, the absence of policy in inclusive education together with ignorance of educators about policy has hampered the execution of inclusion of children with disabilities.

\section{Lack of political commitment}

As Mafa (2012) confirms, decision makers have indispensable role either to dissuade transition from segregated setting to an inclusive mainstream educational system or facilitate inclusion. With this, research participants had a belief that the political leaders could play a vital role to execute any programme including inclusive education effectively. However, the practice in Ethiopia is to the contrary. As the finding reveals, lack of commitment is observed among political leaders to ensure inclusion of children with special needs. The finding evidenced the absence of guideline, the only $4 \%$ school population of CWDs and sceptic understanding of the concept of inclusive education among leaders to show the prevalence of the reluctance of the government to execute inclusive education in the country. The reluctance of political leaders has resulted in insufficient budget allocation, inadequate procurement of adapted school materials, human resource, and development of inclusive guideline. All these have hindered the realisation of inclusion of children with special needs. Similarly, Mafa (2012) found out political reluctance as a barrier to execute inclusive education in Zimbabwe. For him, lack of political commitment could deny adequate resource allocation to educate children with special needs in regular schools.

\section{Conclusion}

Based on the findings of the research, the following conclusions have been drawn. At Mesolevel, the observable and the prevalent lack of collaboration among stakeholders in education; such as teachers, school administrators and the community members as a whole obstructed the inclusion of children with disabilities in the system. The inconsistent data and structural problems at Exo-level have also obstructed the inclusion of children with disabilities. Again, though the macro-level has no direct interaction with the child with disability, the finding revealed how governmental decisions obstructed the execution of inclusion at Macrolevel. Hence, the absence of mandatory inclusive policy and lack of political commitment excluded children with disabilities from learning together with their non-disabled counterparts. Thus, the theory of ecology of human development helped me to locate where the exclusionary elements stanched within the system.

\section{References}

Adebisi, R.O., Jerry, J. E., Rasaki, S. A. \& Igwe, E. N. (2014). Barriers to special needs education in Nigeria, International Journal of Education and Research, 2(11), 51-462.

American Heritage College Dictionary (3rd ed.). (1993). Boston, MA: Houghton Mifflin.

Bhattacherjee, A. (2012). Social Science Research: Principles, Methods, and Practices. University of South Florida Tampa, Florida, USA. 
Bronfenbrenner, U. (1989). Ecological systems theory. In R. Vasta (Ed.), Six theories of development (pp. 187-249). Greenwich, CT: JAI Press.

Creswell, J. W. (2007). Qualitative Inquiry research Design: Choosing among Five Approaches ( $2^{\text {nd }}$ ed.). Thousand Oaks, California: Sage Publications.

Cortiella, C. \& Horowitz, S. (2014). The State of Learning Disabilities: Facts, Trends and Emerging Issues. New York:National Center for Learning Disabilities.

Lazarevic E. \& Vukasinovic E. (2013). The Role and Place of Parents of CwDs in inclusive education in Serbia, International Journal about Parents in Education. 7(2): 69-78.

Lewis, I. (2009). Reaching the marginalised: Paper commissioned for the EFA global monitoring report (Unpublished paper).

Mafa O. (2012). Challenges of implementing inclusion in Zimbabwe's Education System, Journal of Education Research, 1(2), 14-22

Maguvhe, M. (2015). Inclusive education: A transformation and human rights agenda under spotlight in South Africa, African Journal of Disability, 4 (1): 112-126.

Malak, S. (2013). Inclusive Education Reform in Bangladesh: Pre-Service Teachers'Responses to Include Students with SEN in Regular Classrooms, International Journal of Instruction: 6, (1): 1308-1470.

Martin N. \& Marshall, M. N., (1996). Sampling for qualitative research. in Family Practice, Vol. 13, No. 6 Oxford University Press.

MoE. (2008). The Development of Education: National Report of the Federal Democratic Republic of Ethiopia, Addis Ababa.

MoE. (2012). Special Needs education strategy; Addis Ababa.

MoE. (2015). Education sector development programme V. Programme action plan. Addis Ababa, Ethiopia.

MoE. (2016). Generaleducationstatistical abstract. Federal Democratic Ethiopia, Addis Ababa.

Mukhopadhyay, S. (2014). Botswana primary schools teachers' perception of inclusion of learners with SEN, Journal of Research in SNE; 2, 1, 33-42.

Naicker, S. (2006).) From policy to practice: a South-African perspective on implementing inclusive education, International Journal of Whole Schooling, 3(1), 59-78.

Thomas, G. (2013). A review of thinking and research about inclusive education policy, with suggestions for a new kind of inclusive thinking, British Educational Research Journal 39(3), 473-490.

Tirussew, T. (2005). Disability in Ethiopia: Issues, Insights and Implication: Contextualising, Disability. Addis Ababa: Addis Ababa University printing press.

Tirussew, T. (2006). An Overview of Inclusive Development in the Last Fifteen Years in Ethiopia. In H. Salvolainen, M. Matero \& H. Kokkala (eds) When All Means All: Experiences in Three African Countries with EFA, Hakapain Oy, Helsinki, Finland.

UNESCO. (1994). Salamanca Statement and Framework for Action on Special Needs Education, Special education programme. Paris: UNESCO.

UNESCO. (2003). Overcoming Exclusion Through Inclusive Approaches in Education: a Challenge and Vision Conceptual paper. Paris: UNESCO.

UNESCO. (2005). Guidelines for Inclusion: Ensuring Access to EFA. Paris: UNESCO.

UNESCO. (2009). Policy Guidelines on Inclusion in Education. Paris: UNESCO.

Van Manen, M. (1990). Researching lived experience: Human science for an action sensitive pedagogy. London: the University of Western Ontario.

Wapling L. (2016). Inclusive Education and CWDs: Quality EFA in Low and Middle Income Countries. CBM: Nairobi 
World Vision. (2007). Including the Excluded: Integrating disability into the EFA Fast Track Initiative processes and National Education Plans in Ethiopia, World Vision UK: Milton Keynes.

Wook, Y. (2013). Inclusive Education in Korea: Policy, Practice, and Challenges, Journal of Policy and Practice in Intellectual Disabilities: 10(2), 79-81.

World Health Organization. (2011). World Report on Disability. Geneva Switzerland.

Zelalem, T. (2018). School challenges of students with visual impairment in Weldeya primary schools of Ethiopia, International Journal of Special Needs Education; 33(3), 510-524.

\section{Biographical notes:}

Zelalem Temesgen, PhD - Assistant prof in special needs education. In 1996, graduated from Institute of language studies, Addis Ababa University. In 2007, completed his graduate from Addis Ababa university, School of graduates. In 2018, he has received his doctoral degree from University of South Africa, College of education, Department of inclusive education. Since 2008, he has been teaching special needs education at Bahir Dar University. His publications are: School challenges of students with disabilities in Weldeya primary schools of Ethiopia, international Journal of special needs education; Co-curricular participation of students with disabilities in Ethiopia Journal of Pedagogical research; The journey of special need education in Ethiopia An overview, journal of Education and Practice. The effect school barriers against school participation of students with visual and physical disabilities; the case of Gondar primary school of Ethiopia. International journal of E-reflection. 